\title{
Presencia, posibilidades y posiciones de la escritura errante en México: el caso Campobello
}

\author{
Kristine Vanden Berghe \\ Université de Liège, UC-Mexicanistas
}

En su libro La escritura errante: ilegibilidad y políticas del estilo en Latinoamérica (2016), Julio Prieto no incluye ningún texto mexicano, lo cual suscita la interrogante de si esta ausencia refleja una marginalización mayor de la llamada "mala escritura" latinoamericana en unas literaturas nacionales que en otras. En este ensayo doy un primer paso para abordar esta pregunta, argumentando que México cuenta con una digna representación de dicho tipo de escritura en Cartucho (1931). En este texto, Nellie Campobello elabora su escritura errante gracias a una serie de procedimientos estilísticos que señalan las carencias del cuerpo social y que apuntan a una variada red de textos y tradiciones que podrían haber influido en ella. El análisis que propongo desemboca en algunas reflexiones acerca de la relación entre la escritura errante, la narrativa del norte de México y las normas impuestas desde el centro geográfico y cultural del país para tratar de forjar un canon literario nacional.

Palabras clave: Antiguo Testamento, Nellie Campobello, corrido, escritura errante, literatura del norte, literatura mexicana, parataxis, romance.

In his book La escritura errante: ilegibilidad y politicas del estilo en Latinoamérica (2016), Julio Prieto does not include any Mexican text. This raises the question whether this absence reflects a tendency toward a stronger marginalization of the so called Latin American "bad writing" in some national literary canons than in others. In an attempt to answer this question, I argue that Mexico has a very worthy representation of the "bad writing" practice in Cartucho (1931). In this book, Nellie Campobello uses a series of stylistic devices that highlight the shortcomings of the social body and point to a varied network of texts and traditions that may have influenced her. The analysis I develop results in a hypothesis about the relationship among deviant writing, the narrative of the North of Mexico, and the norms 
imposed from the geographical and cultural center of the country in order to forge a national literary canon.

Keywords: "bad writing", ballad, Nellie Campobello, corrido, Mexican literature, narrative style of northern Mexico, Old Testament, parataxis.

En la portada del libro titulado La escritura errante: ilegibilidad y políticas del estilo en Latinoamérica que Julio Prieto publicó en 2016, George Yúdice compara el texto con La ciudad letrada, de Ángel Rama, y Desencuentros de la modernidad en América Latina, de Julio Ramos, augurándole un futuro prometedor por su "insight and sweep". Es posible que, por la profundidad de sus análisis, el libro tenga amplia repercusión, y aunque también impresiona su extensión, quiero detenerme un momento en la palabra Latinoamérica en su título porque a esa designación espacial corresponde un objeto de estudio más limitado: Prieto no analiza ninguna creación cultural proveniente de áreas que se ubican más al norte que el Perú; es decir que están ausentes de su libro las producciones artísticas desde el Ecuador y Colombia hasta México. Esto no es una crítica, puesto que el análisis abarca mucho. Pero la ausencia sí suscita la duda de si la escritura errante no ocuparía una posición distinta en la historia de unas literaturas latinoamericanas que en otras. En un artículo de 2011, Prieto dijo que, en efecto, el Río de la Plata era uno de los focos de más intensa producción de prácticas de mala escritura.

En este artículo abordo la interrogante si la acotación geográfica del libro refleja una marginalización mayor de este tipo de escritura en determinadas regiones o tradiciones nacionales, in casu, en la mexicana. Si fuera así, esto implicaría que los diferentes campos literarios -o incluso, de manera más general, culturales- en América Latina evalúan de formas distintas las producciones estilísticamente menos clásicas y más críticas hacia el orden político y social. Concretamente, la ausencia de México en el libro de Prieto ilustraría entonces que la sociedad mexicana o, al menos, quienes orientan las normas que dominan en el campo cultural y tienen el poder de legitimación prefieren modos de escribir más clásicos y menos disruptivos y, al mismo tiempo, menos contestatarios del statu quo en comparación con lo que pasa, por ejemplo, en el Río de la Plata.

Doy un primer paso hacia tal cuestionamiento, enfocándome en el caso de Nellie Campobello, cuyo libro de estampas sobre la Revolución en el norte del país, Cartucho (1931), es una digna representación de la escritura errante. Después de analizar los 
Vanden Berghe, Presencia, posibilidades y posiciones de la escritura errante en México

rasgos que, en esta obra, caracterizan su "mala escritura", elaboro el inicio de lo que podría llegar a ser una cartografía de tradiciones y textos que pueden haber influido en ella y, posiblemente, de manera más global, en la escritura errante del norte mexicano. Termino por proponer una hipótesis respecto de la ausencia de la literatura mexicana en el libro de Prieto, ausencia que es ilustrativa de las relaciones entre cultura y política y centro y periferia en el país. Antes, sin embargo, cabe explicar brevemente el concepto de escritura errante.

Estéticamente hablando, es una escritura que contrasta con los modelos de economía clásica como paradigmas de la buena literatura porque pone en evidencia una falta, razón por la cual a menudo ha sido incomprendida. Según Prieto, "la errancia y la falta estarían en la raíz del arte moderno" (Prieto 2016, 15), problematizan la posible eficacia comercial de la literatura y generan una distintiva marca autorial que tiene la potencialidad de inscribirse de forma duradera en el campo literario. En la literatura, la errancia implica la voluntad de llevar la escritura a sus límites mediante formas agramaticales y hasta ilegibles; en la música, la disonancia y la arritmia son rasgos usuales suyos, y en la pintura se refiere a cuadros de los que la gente dice que están "mal pintados". La reivindicación de formas imperfectas, el uso antiacadémico de la lengua y la ausencia de cohesión narrativa son características suyas, a menudo también vinculadas a las vanguardias que surgieron durante las primeras décadas del siglo $\mathrm{XX}$, contexto en el que Campobello publicó Cartucho.

El gesto de escribir mal es clave en la configuración de las modernidades periféricas y adquiere un perfil específico en América Latina donde entra en diálogo con las prácticas y los imaginarios de emancipación: implica una dimensión extraestética en la medida en que significa una "ética y política de un movimiento hacia el otro" (Prieto 2016, 14). Este "otro" aparece en una posición de subalterno: "Podríamos sintetizar la inflexión política del gesto de escribir mal en la articulación de una poética del abandono -una puesta a la deriva de hábitos disciplinarios y convenciones estéticas y discursivas- con una política del abandono -una práctica que responde a los abandonos y fallas del cuerpo social-" (14). Las escrituras que constituyen el corpus central del libro de Prieto son Los lanzallamas de Roberto Arlt, la poesía de César Vallejo, el cine de Glauber Rocha y los textos neobarrocos de Néstor Perlongher, Osvaldo Lamborghini y Severo Sarduy. En comparación con esos textos, las estampas de Cartucho están "menos mal" escritas, son menos herméticas, sofisticadas y artificiosas. A pesar de esto, plasman la poética y la política del abandono tal y como las entiende Prieto. 


\section{Desorden, parataxis, elipsis}

Mientras que, durante décadas, la obra de Campobello fue leída poco y, además, en función de sus contenidos, en los últimos veinte años se ha acrecentado una literatura crítica que la considera a partir de coordenadas de tipo estilístico, destacando en particular los recursos destinados a crear un efecto de oralidad (Rodríguez 1998; Parra 2005; Marco González 2013; Martínez 2015). Aunque los mexicanismos y arcaísmos contribuyen a este efecto, el hecho de que en ocasiones aparezcan entrecomillados ubica a la escritora en la tradición de los escritores regionalistas que no dejaban de confirmar lingüísticamente su lugar más elevado con respecto al bajo pueblo. ${ }^{1}$ En cambio, el estilo de Campobello es más innovador en el nivel superior al del léxico, revelándose ante todo en el nivel sintáctico y discursivo, mediante la creación de un desorden en la narración y -de una forma aún más sistemática-en la parataxis y la elipsis.

Prieto asigna al calificativo errante dos sentidos distintos que se complementan: el sentido del error y el del movimiento poco ordenado: "Un errar -en el sentido de lo que es puesto a la deriva-" (2016, 13). Ejemplo de ese errar es "Las cinco de la tarde", una de las veinticuatro estampas que se añaden en la segunda edición de Cartucho (1940) a la de 1931, que contaba treinta y tres. Ilustra el escribir errantemente por la manera en la que la narradora libra la información sobre los hechos. La estampa consta de tres párrafos:

Los mataron rápido, así como son las cosas desagradables que no deben saberse.

Los hermanos Portillo, jóvenes revolucionarios, ¿por qué los mataban? El camposantero dijo: "Luis Herrera traía los ojos colorados, colorados, parecía que lloraba sangre". Juanito Amparán no se olvida de ellos. "Parecía que lloraba sangre".

A los muchachos Portillo los llevó al panteón Luis Herrera, una tarde tranquila, borrada en la historia de la Revolución; eran las cinco (Campobello 2000, 68).

1. Por una parte, ya que no poseemos el manuscrito, no podemos descartar que se trata de una intervención en el proceso editorial que es ajena a la voluntad de la autora. Por otra parte, en la segunda edición de 1940, los mexicanismos y arcaísmos son reemplazados por palabras menos marcadas, según la mayoría de los críticos, debido a la intervención de Martín Luis Guzmán. Tabea Alexa Linhard piensa, como Irene Matthews, que Campobello introdujo los cambios posiblemente para presentar un texto más domesticado y femenino (Linhard 2005, 171). 
Los personajes se nos vienen sin respeto hacia la lógica de su presentación. La primera frase se refiere a unos muertos con el pronombre los. Su identidad se especifica en la siguiente cuando la narradora dice que se trata de "los hermanos Portillo". En el segundo párrafo, se presentan dos personajes, el camposantero y Luis Herrera, pero no sabemos cuál es el nombre del primero ni la función del segundo. La repetición de la frase "parecía que lloraba sangre" sugiere que el camposantero es Juanito Amparán, y en la tercera parte resulta claro que el que llevó a enterrar a los hermanos Portillo es Luis Herrera. La poca sistematicidad con la que se brinda la información contribuye a crear un efecto de espontaneidad, ya que suscita menos el recuerdo reconstruido que una fuerte emoción aún no domesticada. Al mismo tiempo, el caos que caracteriza la enunciación evoca el caos de la Revolución y la impropiedad de dar cuenta de su curso mediante un relato ordenado en el cual las acciones se sigan dominadas por una lógica coherente. ${ }^{2}$ También da cuenta de la dificultad de interpretarla por la falta de entendimiento o por el impacto traumático que causó. Por lo tanto, entre el texto y sus referentes se tejen relaciones que demuestran que el desorden del discurso está al servicio de una voluntad de crear una visión compenetrada con los hechos.

En el nivel sintáctico llama la atención el uso sostenido de la parataxis: Campobello prescinde de conjunciones que introduzcan subordinadas y expliciten las relaciones lógicas entre las frases o, dentro de ellas, entre sus distintos componentes. "Las cinco de la tarde" propone los datos exiguos mediante un encadenamiento de breves oraciones mayormente principales cuya conexión sintáctica es pobre. En las otras estampas a veces aparecen conectores, pero son escasos y siempre sencillos; en cambio, sí aparecen oraciones coordinadas mediante la conjunción $y$. Tal como el desorden en el nivel del discurso, este rasgo en el nivel de la sintaxis contribuye a sugerir cuán pequeño es el horizonte de la narradora, que es una niña de tierna edad, y cuán lejos estaba de poder ordenar sus materiales y relacionar los hechos de un modo lógico. El efecto creado por la parataxis es parecido al que tiene el desorden, por cuanto a su vez aumenta la necesidad de intervención del lector que debe encargarse de lo que usualmente hace el narrador: señalar las articulaciones entre las partes y establecer las conexiones entre las frases.

2. Partiendo de otro marco teórico, Lucas Izquierdo, al contrario, estima que el lenguaje de Campobello procura suturar el vacío ideológico de la Revolución (2013, $351)$. 
A menudo los textos paratácticos integran compensaciones para las elipsis mediante una "renarrativización", y una de ellas es la repetición (Perelman 1993, 18). En "Las cinco de la tarde" la repetición aparece bajo tres formas, compensando así el esfuerzo que supone reconstruir el sentido debido al estilo paratáctico y la estructura caótica. Primero, narrar historias aparece como una repetición de estas mismas historias contadas en boca de distintas personas: aquí la narradora cuenta lo dicho por el camposantero. Se trata de una forma de repetición que Jorge Fornet ha calificado de "juego de espejos que multiplica hasta el infinito los orígenes de la narración" (1994, 15), y que Max Parra ha situado en el marco del pueblo chico (2005). Según Ana Marco González (2013, 172), esta forma de repetición explica la abundancia de los verba dicendi, aunque la estampa que hemos citado también ilustra que a menudo son suprimidos. En segundo lugar, el valor superlativo se expresa en el nivel léxico mediante la repetición del adjetivo ("colorados, colorados"), repetición bastante recurrente en el libro. Por último, la repetición, en tan pocas líneas, del verbo matar ("mataban", "mataron") y de la referencia a la Revolución ("Revolución", "revolucionarios") ilustra la redundancia, como también lo hace la repetición de la frase "Parecía que lloraba sangre".

Entre el desorden paratácticamente expresado y la repetición se establece así una relación que es al mismo tiempo tensa y complementaria: ambos evocan la espontaneidad de la expresión y la poca elaboración del discurso oral, pero mientras que el desorden y la parataxis constituyen gestos de despojamiento retórico de acuerdo con la índole áspera e incomprensible del referente y dificultan la memorización, la repetición constituye un preciado recurso mnemotécnico. Por otra parte, cabe recalcar que, como en la obra de Juan Rulfo de la que es un antecedente directo (Vanden Berghe 2017), no es la voz espontánea del pueblo la que aquí escuchamos sino su evocación mediante un trabajo estilístico intenso. La repetición literal de la oración "Parecía que lloraba sangre" es un sencillo ejemplo de ello, pues en el lenguaje oral la reiteración no suele ser idéntica (Pacheco 2016, 123). Además, el título de la estampa y su última frase que lo retoma, "Eran las cinco", es posiblemente un homenaje a Elegía por Ignacio Sánchez Mejía de Federico García Lorca, publicado cinco años antes, en 1935, y cinco años después del breve encuentro entre el poeta andaluz y la escritora mexicana en La Habana -encuentro que ésta comenta en el prólogo a su obra reunida- (Campobello $2006,101)$. A pesar de que presentara su obra como un testimonio directo de la realidad, Campobello no deja de ser una tejedora cuyo 
Vanden Berghe, Presencia, posibilidades y posiciones de la escritura errante en México

trabajo dialoga con otros textos y tradiciones, como argumento más adelante.

\section{Literaturas dietéticas y carencias del cuerpo social}

La cantidad mínima de la información y el carácter escueto y elíptico del estilo elaboran una forma basada en la omisión que, a su vez, se adecúa a los referentes del texto o que deja entrever una presión por parte de estos. Mediante la reducción, Campobello homenajea a los personajes que crea en su ficción y a las personas de las que habla en sus ensayos que se parecen por su constitución delgada. En Cartucho, la pequeña Nellie enseñó sus muñecas al soldado Rafael: "Y pasaba todos los días, flaco, mal vestido. Era un soldado. Se hizo mi amigo porque un día nuestras sonrisas fueron iguales" $(2000,61)$. La narradora siente cariño por este muchacho flaco que "tiene poca carne" (DRAE s.v. "flaco"). Asocia su flacura con la mala calidad de su ropa, sugiriendo que se debe a su pobreza y no del todo a su "falta de resistencia", otra acepción que la palabra flaco puede tener (DRAE s.v. "flaco").

Las manos de mamá (1937), el segundo libro de estampas que Campobello dedicó a la Revolución, refleja honda admiración por su madre, que se pinta tan intrépida como los revolucionarios. Su fuerza no está reñida con su belleza destacada desde las líneas iniciales del libro: "Esbelta como las flores de la sierra cuando danzan mecidas por el viento" $(2006,7)$. A la flacura del soldado Rafael corresponde la esbeltez de la madre, Rafaela, un rasgo que la narradora vuelve a señalar cuando recuerda su muerte: "¿Acaso su esbelta figura vaga, mecida por el viento, allá en la gloriosa calle de la Segunda del Rayo?" (2006, 33). Es cierto que la esbeltez tiene una connotación de belleza que la flacura no tiene; al mismo tiempo, tal y como lo flaco en Cartucho, la esbeltez de la madre se asocia oblicuamente con la carencia y el hambre: "Mamá: fue Usted nuestra artista; supo borrar para siempre de la vida de sus hijos la tristeza y el hambre de pan -pan que a veces no había para nadie, pero no nos hacía falta-" (2006, 17; subrayado en el texto). De nuevo, delgadez, hambre y una expresión de simpatía vienen de la mano.

La misma asociación se encuentra en los retratos de Francisco "Pancho" Villa y Venustiano Carranza que Campobello construyó en su libro Apuntes sobre la vida militar de Francisco Villa publicado en 1940. A pesar de que el título promete un discurso historiográfico neutro, en esos retratos el tono descriptivo es abandonado a favor del ditirambo y la caricatura satírica: 
En el México de entonces, las barbas y los lentes eran parte decisiva en la respetabilidad de las personas. Todavía hoy se cree en estas raras apreciaciones, la mayoría de la gente no olvida su condición de esclavo. Además, la barriga de Carranza quería decir mucho. Los hombres flacos que montan a caballo pueden ser bandidos o cualquier otra cosa, pero un hombre gordo, con barriga, pregona su alimentación a base de chocolate y bizcochos, y si tiene en la nariz poros y venas rojas, esto dice a las claras que toma sus vinos, cosa muy importante para cautivar a los tontos. Los hombres gordos eran entonces más apreciados que los esbeltos, la mayoría de la gente pobre es delgada. Carranza, sin ser propiamente gordo, era un poco panzón, tenía venas en las narices, signo inequívoco de los que comen mucho, y aunque no nos consta que tomara vino, sí tenía muchos poros en la sudorosa e inflexible nariz, bien ancha y llena de grasa. Además, Carranza tenía lentes con arillos de oro y barbas blancas y patriarcales. No era esbelto ni era de la clase pobre (1940, 104; subrayados míos).

Como hacía la niña Nellie en Cartucho con los cuerpos de los revolucionarios, la "historiadora" disecciona el cuerpo de Carranza en un retrato apasionado y desordenado que recalca su gordura: marca exterior de su derrumbe moral que sugiere cómo un cuerpo corpulento encarna mal el cuerpo del poder. La descripción de Villa da la medida del antagonismo: ya que era difícil decir que era delgado, Campobello lo retrata en la compañía de sus muchachos, "pelados", a los que contrasta con el volumen y la hinchazón de las tropas de Carranza, que "hacían bulto" y se describen con un aumentativo: "Esos rancherotes eran muchos y representaban al pueblo. Hacían bulto, eran un desprestigio para México, para el México de sus mentalidades; tener hombres como Pancho Villa y sus pelados, era, según ellos, terrible, había que quitarlos" $(1940,105) .^{3}$ El sentimiento de cariño que expresa hacia lo pelado, delgado, esbelto o flaco recorre toda la obra de Campobello, proyecta la condición social de los personajes sobre su físico y es coherente con su estilo, que también prescinde de lo superfluo.

Constatemos a propósito que Prieto asocia su concepto de escritura errante con el paradigma de lo delgado. Lo hace brevemente hacia el final de su libro y en una nota en pie de página; sin embargo, parece querer abrir hacia otras lecturas en función del criterio de la delgadez, afín a las escrituras errantes:

Las escrituras errantes adelgazan: en cuanto prácticas de rarefacción y carencia, ponen a régimen las abundancias de los escritores canónicos. Alguna vez habría que explorar esta hipótesis: la literatura latinoamericana

3. Para un análisis más sistemático de los retratos de Villa en la obra de Campobello, véanse Parra (2005) y Gutiérrez de Velasco (2006). 
propone una pugna entre escrituras redondas y escrituras "adelgazadas", una soterrada discordia entre gordos y flacos: Darío vs. Vallejo; Macedonio vs. Borges; Lezama vs. Piñera; Lamborghini o Gombrowicz vs. Borges; Perlongher vs. Lezama. [...] Claro que para esa conjetural teoría de la literatura "dietética", que opondría escrituras de letra llena y escrituras de letra magra, Borges sería una figura ambigua: dada cierta inclinación a la frugalidad al denuesto de lo literario, a la vez que como antagonista y notorio detractor del "escribir mal", también podría considerárselo como una especie de oblicuo precursor $(2016,263 n 10)$.

"Rarefacción y carencia", puesta "a régimen" en escritura de letra magra, "denuesto de lo literario", son sendas características del estilo de Campobello que posiblemente han contribuido a apartarla del canon de la literatura mexicana, de lo que Prieto llama "las abundancias de los escritores canónicos”. De lo que precede se deduce también que el elogio que hace Campobello de la delgadez no se arraiga, al menos no en primer lugar, en una evaluación según criterios estéticos. Más bien deja constancia de su preferencia por los mal alimentados y peor vestidos, a la vez que ilustra su aversión de los que se engordan personalmente, los enemigos del pueblo o sus traidores: la elipsis y la parataxis, rasgos de la errancia poética, se ponen al servicio de una errancia de tipo político que supone, según Prieto, un movimiento hacia grupos históricamente excluidos del orden hegemónico.

El autorretrato que la escritora construye en la estampa inicial de Cartucho sugiere que se propone asumir este movimiento personalmente. El que esta estampa abra el volumen y le dé su título es apropiado en la medida en que incluye in nuce sus rasgos esenciales: la desnudez de la parataxis, la mezcla de filosofía y dicción popular, y un retrato ficcional de una narradora infantil que encarna a la autora. ${ }^{4}$ En ella Campobello se retrata como una niña que está "jugando debajo de una mesa" desde donde pronuncia una sentencia que sin duda ha oído decir a algún adulto cuyo discurso reproduce (otra repetición). El escenario corresponde a una voluntad de ambientación, pero trasciende lo decorativo.

Presentándose como una niña pequeña, la autora se elabora un autorretrato afín al del flaco Rafael, la esbelta Rafaela y los pelados de Villa, por cuanto también adopta un volumen corporal reducido. Al paradigma de la delgadez se suma así el de la pequeñez en una representación de lo popular. Su lugar de enunciación debajo de la mesa es más que un complemento de lugar, porque señala desde el inicio del libro la perspectiva simbólica, subalterna, desde la cual los

4. En la segunda edición, el título "Cartucho" se transforma en "Él". 
hechos serán enfocados. Además de poder leerse como una alusión a Los de abajo, ${ }^{5}$ esta posición física traduce un posicionamiento ideológico y social que articula lo popular, infantil, femenino y norteño. Su tierna edad y su ubicación debajo de la mesa también pueden interpretarse en términos de una representación de la oralidad que es vista comúnmente como una forma evolutivamente inferior. De esta manera, mientras el desorden narrativo es significativo de la dificultad de hablar de la Revolución, el estilo delgado y errante -"a ras de lengua" (Prieto 2016, 22) o de una ilegibilidad "pedestre" (217)- apunta a la voluntad y al deber de hacerlo desde los márgenes y en defensa suya. El lugar donde se ubica el personaje autoficcional desde el principio del libro ilustra así lo dicho por Prieto, quien, en este particular, se apoya en Michel de Certeau: "Las prácticas de mala escritura serían 'tácticas' para hablar desde un margen, desde posiciones de visibilidad incierta" (Prieto 2016,16 ), prácticas que, de manera paradójica, obedecen a un deseo de visibilizar este margen. ¿Y qué lugar más marginal y de menor visibilidad que el de una niña sentada debajo de una mesa?

\section{Conciencia y voluntad}

El concepto de escritura errante supone que el escritor practica el error de forma consciente y refinada, lo cual, en el caso de Campobello, pocas veces ha sido interpretado así. Todo lo contrario, su inscripción periférica en el campo literario -su ocupación principal era la danza- y su condición de mujer alentaban a concebir su obra más bien como el resultado aleatorio de una especie de espontaneidad femenina. Alfonso Núñez Alonso escribió que Cartucho no tenía preocupaciones literarias (en Rodríguez 1998, 263), y José Muñoz Coto consideró que "no se ha tomado el trabajo de ser original" porque escribe como es (en Vargas Valdés y García Rufino 2013, 508), comentarios que demuestran más que todo que Campobello logró crear de una forma convincente la impresión de ausencia de elaboración. Además, la entrevista que le hizo Emmanuel Carballo en 1958 y el prólogo autobiográfico para su obra reunida, publicada en 1960 con el título Mis libros, dan a entender lo que ya han sugerido a su modo los análisis precedentes: es decir que su mala escritura es el fruto de una búsqueda de un abandono poético para dar cuenta de otro en el nivel político.

5. Aunque Campobello dijo no haber leído ningún libro sobre la Revolución antes de escribir Cartucho, muchos han señalado que no siempre debemos creerle (Vanden Berghe 2016). 
Vanden Berghe, Presencia, posibilidades y posiciones de la escritura errante en México

En la entrevista con Carballo, Campobello caracteriza su obra en dos ocasiones a partir de lo que está ausente en ella, dando a entender así que buscó crear un lenguaje escueto. La primera ausencia a la que apunta es el adjetivo: "En mis libros casi no uso adjetivos. Estos los emplean los maestros, no las escritoras sencillas como yo" (Carballo 1965, 334). También subraya el carácter "dietético" del léxico que usa, diciendo que es "reducido" y que da "simplemente el santo y seña de las cosas, de las personas" (334). La idea de delgadez ("reducido") y sencillez ("simplemente") resuena aquí doblemente. En el prólogo para Mis libros, la autora apunta a la dificultad que escribir le supuso, con lo cual caracteriza su obra como el resultado de una búsqueda complicada: "Entonces sostuve conmigo misma algo así como un forcejeo: epodría decir, con voz limpia, sin apasionamiento, las verdades que formaban parte de mi historia familiar?" (Campobello 2006, 100-1) y aún, "Quererlo no me hacía capaz; necesitaba yo una disciplina" (103). Estos testimonios sugieren que la poética del abandono es el resultado de un esfuerzo de la autora por encontrar las formas adecuadas. Por esto, Gabriela De Beer acierta cuando dice: "La palabra disciplina con sus connotaciones de exactitud, rigor y forma constituye la esencia estilística de Cartucho" (1979, 215; subrayado en el texto).

De forma paralela, surge la inquietud de saber si también buscaba sugerir una política del abandono: ¿Le alentaba realmente la motivación de replantear los términos de lo social en sus textos? Al respecto, son significativas las afirmaciones en las que confiere un valor testimonial a sus libros, subrayando que los hechos relatados fueron vividos por ella, lo cual se pone garante de su historicidad. En su ensayo autobiográfico, resalta su compromiso con la verdad: "Amante de la verdad y de la justicia, humanamente hablando, me vi en la necesidad de escribir" (Campobello 2006, 96-97). La verdad, un ideal que marca toda su obra y del que dice que la originó, supone hacer justicia a los injustamente olvidados o calumniados. Dijo a Carballo: "Lo escribí para vengar una injuria. Las novelas que por entonces se escribían, y que narran hechos guerreros, están repletas de mentiras contra los hombres de la Revolución, principalmente contra Francisco Villa" (Carballo 1965, 336). ${ }^{6}$

Campobello presenta esta justa verdad como una alternativa a la verdad oficial, siempre al servicio de los intereses establecidos, y como una verdad objetiva que ennoblece al pueblo. Cierto, en

6. Sobre este tema y el lugar particular que ocupa Campobello entre los demás escritores de la Revolución, se encuentran ideas sugerentes en Aguilar Mora (1991), Avechuco Cabrera (2017) y Sánchez Prado (2018). 
ocasiones defiende lo que llama "mis verdades" $(2006,92)$ y "mi verdad" (145), utilizando un posesivo con el que parece introducir cierta forma de perspectivismo. Sin embargo, esta interpretación iría a contracorriente de otras afirmaciones suyas, por lo cual el posesivo más bien implica una oposición a una "verdad" ajena que es mentira. Poniendo en juego un discurso que enfoca la cuestión de la verdad y la mediación, Campobello ambiciona claramente que su intervención en el campo literario tenga una incidencia política que sea emancipadora. Esta intervención toma la forma de un discurso contra los que tienen el poder político, pero también contra quienes apoyan este poder desde el canon literario: "Los escritores mexicanos, casi todos burócratas al servicio del régimen, ocultan en sus libros los problemas reales del país; les falta el valor de denunciar el mundo en el que viven y que los oprime" (Carballo 1965, 334). Tales afirmaciones desdicen la imagen que se pudiera tener de una mujer que escribió de una manera aleatoria y se dedicó algo azarosamente a la escritura.

\section{Tejedora en un vasto taller histórico}

Varios indicios sugieren que Campobello pudo crear su estilo peculiar gracias a su familiaridad con otros textos que formaban el depósito de tradiciones escritas y lecto-orales en circulación en el norte de México, especialmente los corridos, el romancero y la Biblia. Constituyen discursos importantes en "el vasto taller histórico de la sociedad americana" (Rama 2007, 24) dentro del cual la autora escribía, y tienen rasgos comunes que se han aprovechado en Cartucho.

Es sabido que en el aprendizaje literario de Campobello ha intervenido su contacto íntimo con los corridos, que conocieron una época de auge durante la Revolución mexicana (Parle 1985; Parra 2005; Marco González 2013): Cartucho incluye alusiones a corridos y fragmentos de corridos, compartiendo con ellos una serie de recursos característicos de la literatura popular, tales como son la precisión topográfica, el carácter concreto de la temporalidad y la visión comunitaria. Sobra decir que la elaboración estilística de los corridos es globalmente menos sofisticada y que sus letristas, que a menudo son anónimos, no suelen aspirar a inscribir su letra de forma duradera en el canon literario, lo cual los aleja del concepto de la errancia. En cambio, a este concepto los acerca el hecho de que en ellos el abandono poético aparezca como la expresión formal de un posicionamiento político: paratácticos y elípticos (Herlinghaus 2009) suelen encomiar a personajes populares desprestigiados por el establishment e implican una gran desconfianza hacia este, rasgos 
Vanden Berghe, Presencia, posibilidades y posiciones de la escritura errante en México

a los que Campobello habrá sido sensible. Catalina Héau de Giménez ha señalado este último rasgo como lo que define al género: es un "vector ideológico de los grupos subalternos, como signo de reconocimiento y de identificación entre los mismos y como archivo de la memoria colectiva" $(1991,38)$. Su definición es retomada ampliamente por otros investigadores que hacen también suya la idea de que este posicionamiento es separable, y debe separarse, de su "contenido": "El corrido debe definirse no por las características (temáticas, estéticas, etcétera) de su contenido, sino por su representatividad sociocultural, es decir, por su referencia al pueblo como portador y soporte" (36). Nuestro análisis de Cartucbo y el marco de la escritura errante, al revés, postulan la impropiedad de separar formas y posicionamientos sociopolíticos, ya que vienen estrechamente unidos.

También son masivas las coincidencias estilísticas entre Cartucho, el romancero y el Antiguo Testamento, lo cual queda claro cuando abordamos estos últimos a partir del análisis hecho por Erich Auerbach en su clásico Mimesis: la representacion de la realidad en la literatura occidental (primera edición en alemán de 1946). Al estudiar el devenir de las literaturas occidentales, Auerbach distingue entre lo que designa como estilo clásico y estilo primitivo. Define el estilo clásico a partir del ejemplo de los textos homéricos, en los que aparecen

en plena luz perfectamente conformadas sus interrelaciones, sus entrelazamientos temporales, locales, causales, finales, consecutivos, comparativos, concesivos, antitéticos y condicionales, de modo que se produce un tránsito ininterrumpido y rítmico de las cosas, sin dejar en ninguna parte un fragmento olvidado, una forma inacabada, un hueco, una hendidura, un vislumbre de profundidades inexploradas (Auerbach 2011, 12).

Al contrario, el estilo primitivo se caracteriza por la ausencia de relato ordenado, la falta de conexión sintáctica clara entre las partes, lo mucho que queda a medio hacer o en la penumbra. Ya que se desdibujan los entrelazamientos lógicos, la exposición está llena de lagunas y saltos: "Realce de unas partes y oscurecimiento de otras, falta de conexión, efecto sugestivo de lo tácito, trasfondo, pluralidad de sentidos y necesidad de interpretación, pretensión de universalidad histórica, desarrollo de la representación del devenir histórico y ahondamiento en lo problemático" (29). Señalemos que en su primer análisis de un relato primitivo Auerbach destaca la escasez de adjetivos y epítetos (14-16).

Uno de los textos que analiza en función de su estilo primitivo es el Cantar de Roldán, que se particulariza por estar lleno de enigmas 
que el poema mismo -cuyos hechos están expuestos con nitidez paratáctica- no explica (99). A su modo de ver, avanza "con sacudidas hacia adelante y hacia atrás" (103), parte "el devenir en pequeños fragmentos" (103) y no expresa gramaticalmente "las relaciones modales que existen entre sus palabras" (107). El análisis que Auerbach hace de los rasgos del estilo primitivo en el romance demuestra cuán grande es la coincidencia con la escritura errante de Campobello. En principio, esto no debe sorprender ya que el romance es uno de los principales antecedentes del corrido (Custodio 1975; Mendoza 1954), por lo cual habrá influido en Campobello a través de su familiaridad con este género musical. Pero su influencia también puede haber sido directa: que la escritora conociera ciertos romances lo hace pensar, por ejemplo, el nombre de la muñeca de la narradora, Pitaflorida, que recuerda al de Rosaflorida, un romance que, según Blanca Rodríguez, "quizá haya sido cantado o recitado por el conquistador del siglo XVI, como tantos otros que pervivieron en los labios del pueblo" $(1998,40)$. El romancero caló hondo en la imaginación popular norteña, y su presencia en la obra de Campobello debería estudiarse con mayor sistematicidad.

La tercera tradición a la que alude Cartucho es la bíblica, y hay razones para creer que a Campobello le impactó el Antiguo Testamento a cuyo estilo primitivo Auerbach dedica las páginas iniciales de Mimesis. En el relato del sacrificio de Isaac,

las figuras están trabajadas tan sólo en aquellos aspectos de importancia para la finalidad de la narración, y el resto permanece oscuro; únicamente los puntos culminantes de la acción están acentuados, y los intervalos vacíos; el tiempo y el lugar son inciertos y hay que figurárselos; sentimientos e ideas permanecen mudos, y están nada más que sugeridos por medias palabras y por el silencio (Auerbach 2011, 17).

Varias circunstancias hacen pensar que la prosa paratáctica y elíptica de Campobello haya sido influenciada por el estilo veterotestamentario. La primera es contextual: la población del norte tenía un profundo conocimiento de la Biblia, que se leía en su versión protestante, probablemente la de Reina Valera, cuya traducción es esmerada y resalta porque adopta una lengua popular (Rodríguez 1998, 37-39). ${ }^{7}$ Por su parte, en su trabajo titulado La Cristiada,

7. Según Carlos Pacheco, Walter Ong ha contrastado la traducción más antigua de la Biblia con la de 1970, en la que el estilo paratáctico se perdió debido a que los lectores, menos familiarizados con el contexto y el texto, necesitaban que se les explicaran mejor las cosas. Pacheco señala que, "para la misma palabra hebrea, la traducción más antigua considerada (publicada en 1610) elige la conjunción 
Vanden Berghe, Presencia, posibilidades y posiciones de la escritura errante en México

Jean Meyer señala que en el campo mexicano la vida estaba "fuertemente enraizada en una cultura popular asentada sobre la Biblia, la tradición oral cristiana, los libros de caballería y la prosa cortesana" (1974, 273).

Que Campobello conociera bien el texto sagrado puede deducirse asimismo de sus propias palabras. Hablaba poco de sus lecturas en público (Rodríguez 1998, 41), pero contestó lo siguiente cuando Carballo le preguntó cuál fue el primer libro que leyó: "Aprendí a leer, en casa, para entender la Biblia; casi me sé de memoria muchos pasajes" (Carballo 1965, 333). Esto disipa cualquier duda sobre su profundo conocimiento del texto bíblico: quería entender su contenido y sabía sus palabras. También Cartucho señala el impacto que le provocó su lectura, por ser la Biblia uno de los pocos textos que la autora menciona de forma explícita. ${ }^{8}$ En la primera estampa, la narradora, sentada debajo de su mesa, escucha que el filósofo popular José Ruiz viene a dar cuenta de Cartucho, el joven revolucionario que ya no acudía a la casa. A raíz de las sentencias que José pronuncia en esa ocasión, la niña califica a este personaje en un lenguaje que remite más bien a la autora adulta o a lo que oyó decir a los adultos: "José era filósofo. Tenía crenchas doradas untadas de sebo y lacias de frío. Los ojos exactos de un perro amarillo. Hablaba sintéticamente. Pensaba con la Biblia en la punta del rifle" (Campobello 2000, 47-48).

Entre las frases, completamente paratácticas, no se especifican las relaciones lógicas, por lo cual el lector debe intervenir activamente para construir un sentido. Entre las dos últimas frases puede

copulativa and (y) en lugar de los subordinativos when (cuando), then (entonces), thus (así, por tanto) o while (mientras), preferidos por la versión más moderna de 1970. Debido a la ausencia de un contexto común en la traducción más reciente, se hizo allí imprescindible proveer al lector con una narrativa razonada, donde los eventos estuvieran relacionados causalmente" (Pacheco 2016, 37-38). Aunque Pacheco no lo especifica, es de suponer que Ong se refiera a la traducción inglesa. Si una evolución parecida pudiera constatarse respecto a la castellana, Campobello habría conocido la versión más elíptica.

8. Rodríguez no se detiene en la alusión que comentamos, pero sí señala un reflejo del Libro de los Salmos en Las manos de mamá (1998, 36). En Cartucho, también hay alusiones a la fe religiosa de los personajes, por ejemplo, a las mujeres y los revolucionarios que rezan a la Virgen, a Dios(ito), al Santo Niño de Atocha, a la Virgen del Rayo y a San Miguel. Algunas escenas del libro pueden leerse en función de conocidos episodios bíblicos, como en la estampa "Las tripas del general Sobarzo" donde estas vienen mostradas en una bandeja, como si fuera la cabeza de San Juan Bautista. En cuanto a la madre, encarna la ética cristiana enseñada en el Nuevo Testamento, regida por el principio de la compasión. 
establecerse una relación causal: José hablaba de manera sintética porque le influenció el estilo bíblico. Interpretadas de tal manera, estas frases dan a entender que Campobello se daba cuenta o tenía una intuición certera de la calidad delgada, paratáctica y elíptica ("sintética", dice su narradora) del lenguaje bíblico (según Auerbach, del Antiguo Testamento). Además, a sus palabras se les puede atribuir un valor autorreferencial oblicuo en la medida en que lo que la narradora dice sobre el habla sintética y bíblica de José se aplica al estilo que la misma autora cultiva en el libro que estas frases introducen. Repárese que asocia este estilo con un modo de pensar ("hablaba", "pensaba") de manera que, una vez más, estilo e ideas, abandono poético y abandono político se nos vienen en estrecha unión. En fin, la estampa que puede dar la impresión de ser una narración infantil desordenada o la reproducción directa del habla de comadres y compadres se convierte en un espeso tejido donde confluyen el proverbio popular -la ficcionalización de una mente oral y de una racionalidad alternativa-Los de abajo y los libros bíblicos veterotestamentarios.

La última oración que completa el breve retrato del filósofo popular Ruiz -"Pensaba con la Biblia en la punta del rifle"- tiene la forma de un alejandrino, pues consta de catorce sílabas métricas, se compone de dos hemistiquios de siete sílabas con acento en la sexta y decimotercera sílabas, y entre ambos hemistiquios heptasílabos hay una cesura medial. Aparte de que su forma realza el cuidado con el que Campobello elaboraba su estilo y particularmente sus cualidades rítmicas, la asociación entre dos sustantivos de los dos hemistiquios, "Biblia" y "rifle", abre una pista suplementaria para una lectura de Cartucho en clave bíblica. Sugiere que se aborde la violencia en el libro a partir de su representación en el texto sagrado, más precisamente, en el Antiguo Testamento en el cual está masivamente presente. La manera en la que Campobello describe la violencia es uno de los aspectos más comentados por la crítica de Cartucho, lo cual es lógico porque se trata de un tema prominente -aunque también sorprende porque su autora es una mujer y su narradora una niña de tierna edad que se muestra ocasionalmente impávida ante los hechos más horrorosos-. Una forma alternativa de interpretarla es a través de la familiaridad de Campobello con el Antiguo Testamento, donde la violencia está omnipresente, que está repleto de masacres sangrientas y asesinatos movidos por la ira y la sed de venganza de los hombres y de Dios. Como dice Norbert Lohfink (1990), se mencionan sin disimulos y se narran de manera natural, sin considerarlas en su negatividad, como también pasa a menudo en Cartucho. Además, allí los cabecillas se comportan como el Dios de 
las narraciones veterotestamentarias, que actúa movido por el enojo, castiga despiadadamente a propios y extraños, y aprueba matanzas y asesinatos.

Lo precedente sugiere nuevas maneras de leer la obra de Campobello y abre una cantera por explorar entre quienes se interesan por las escrituras errantes latinoamericanas y mexicanas, convocando a estudiar hasta qué punto abrevan en el estilo paratáctico y elíptico del Antiguo Testamento para crear su abandono poético. ${ }^{9}$ También invita a analizar hasta qué punto la Biblia ha contribuido a presentar el abandono político. Sobre la Iglesia católica, Rama dijo en Transculturación narrativa en América Latina: "En el último tercio del siglo XIX en que se produjo la modernización positivista, llegó a ser el modo expresivo de las reivindicaciones rurales contra la aculturación violenta a que estaban siendo sometidas las poblaciones de las regiones internas" $(2007,85) \cdot{ }^{10}$ En la estela de Rama y acerca del libro sagrado de esa misma Iglesia católica, podríamos decir que el largo periodo de acriollamiento hizo que se desplazara, que, de símbolo de la imposición externa y de la represión colonizadora, pasara a servir a la causa de la defensa de los pobres y olvidados. ${ }^{11}$

9. También exhorta a estudiar la influencia de la Biblia en la literatura en función de criterios estilísticos, por lo tanto, yendo más allá del análisis de personajes y episodios bíblicos. El volumen editado por Daniel Attala y Geneviève Fabry (2016) sobre la presencia de la Biblia en la literatura hispanoamericana cubre gran cantidad de autores y de épocas. Sin embargo, aparte de algunas alusiones al estilo de los Salmos, en ninguna de las contribuciones se presta atención hacia cuestiones de estilo, ni tampoco hay consideraciones sobre la representación de la violencia.

10. Campobello parte de una dicotomía parecida entre la modernidad urbana (acá: escribe en la ciudad de México) y su comarca interior cuando su narradora dice entre paréntesis: "(Todo esto es una suposición inocente, nacida hoy, acá donde las gentes ignoran al Santo Niño de Atocha y al general Tomás Urbina)" (2000, 104).

11. En estos términos, también defendió Rigoberta Menchú su adhesión a la Biblia y el uso que hacía su comunidad de ella, ante la sorpresa de Elisabeth Burgos. A Burgos le parecía contradictorio que los indígenas rebeldes se inspiraran de la Biblia, ya que fue una de las armas principales del colonizador, a lo cual Menchú "responde sin la menor vacilación": "La Biblia habla de un Dios único, nosotros también tenemos un solo Dios; es el Sol, corazón del cielo. Pero la Biblia nos enseña asimismo [ . . . ] que existe una violencia justa, la de Judith que cortó la cabeza al rey para salvar a su pueblo. Igual que Moisés partió con su pueblo para salvarlo, [ . . ] David sirve de ejemplo para integrar a los niños en la lucha. Hombres, mujeres y niños, cada cual encuentra en la Biblia el personaje con quien identificarse para justificar su acción" (Menchú y Burgos 1987, 16). Observemos que Menchú se refiere aquí exclusivamente a escenas del Antiguo Testamento. 


\section{Buenas condiciones para las malas escrituras}

Según lo entiende Auerbach, la parataxis era un modo de narrar primitivo importante hasta la Edad Media europea, que fue sustituido gradualmente por maneras más modernas y finas de describir la realidad a partir de formas hipotácticas. Sin embargo, en la poesía estadounidense desde los años 1970 se manifiesta un auge de lo que se ha venido llamando la new sentence, caracterizada por la misma ausencia de relaciones sintácticas explícitas entre las frases, auge que Bob Perelman adjudica al hecho de que logre dar cuenta de la atomización de la experiencia postindustrial $(1993,313) .{ }^{12}$ Tomados juntos, estos estudios demuestran que la forma paratáctica surge en épocas alejadas entre sí y sugieren que medra en momentos de crisis y desorden político. Al mismo tiempo, podríamos preguntarnos si hay condiciones geográficas y contextos culturales que, de una u otra forma, favorecen la mala escritura paratáctica. La pregunta nos devuelve al principio de nuestra reflexión cuando nos interrogamos acerca de la ausencia de la literatura mexicana en el libro de Prieto. Sobre el particular (y sin que partan del concepto de escritura errante), se han dado respuestas variadas, de las que a continuación resumo tres.

A principios del nuevo milenio, ante el boom de la narrativa del norte de México, el escritor Eduardo Antonio Parra llegó a destacar tres particularidades de esa narrativa: "La omnipresencia del paisaje y del clima en los relatos, la proximidad geográfica de los Estados Unidos que trae como consecuencia los embates de la cultura norteamericana, y el lenguaje característico de los norteños" $(2004,73)$. Al final de su artículo, E. A. Parra vuelve sobre el criterio del lenguaje, subrayando así la importancia que cobra a sus ojos: "Hay en él un ritmo que se basa en una respiración acaso sofocada por los extremos del clima y, por lo tanto, aunque en general es abundante, da una impresión de parquedad, repetitiva y entrecortada" (2004, 76-77). Parece aludir aquí a la parataxis que corta las frases por falta de aliento, al mismo tiempo que se refiere a la compensación por medio

12. Perelman considera que la parataxis es sintomática de la búsqueda de igualdad en los tiempos que corren: a la coordinación sintáctica correspondería una igualdad semántica que se puede poner en relación con un terreno político y moral. Asimismo, "escribir en frases" consiste en emplear una unidad públicamente legible, lo cual también es democratizador $(1993,315)$. De la misma manera en que Prieto asocia el abandono poético con otro en el terreno social y político, Perelman atribuye un valor político democratizador a la poética paratáctica, con la diferencia de que es más fácilmente legible. 
Vanden Berghe, Presencia, posibilidades y posiciones de la escritura errante en México

de la repetición. ${ }^{13}$ Explica la escritura delgada a partir de motivos climáticos y, aunque también se refiere a la cercanía con los Estados Unidos, no confiere mucha importancia a criterios de carácter político o ético.

En cambio, estos criterios están en el meollo de los análisis de Hermann Herlinghaus sobre las expresiones culturales relacionadas con el narcotráfico (2009). Herlinghaus sostiene que el estilo paratáctico de los corridos globales -el narcocorrido y el corrido de la migración- da cuenta de dramas que no terminan nunca (2009, 75): su carácter cronístico y notarial cumple un imperativo ético en el marco del Sur Global (Global South), donde ocurren constantes flujos de personas que intentan sobrevivir en condiciones extremadamente difíciles. En México, estas condiciones del Sur Global surgen sobre todo en el norte del país, norte que ha sido tierra privilegiada para el corrido y, en fechas recientes, el narcocorrido. Es allí donde los dramas humanos relacionados con la Revolución, el narcotráfico y la migración tienen una presencia notable y se expresan mediante una escritura paratáctica.

Un tercer punto de vista lo ofrece el escritor norteño e investigador en la Universidad Autónoma de Baja California Heriberto Martínez Yépez (2015) al tratar la narco-novela contemporánea. La caracteriza en función de una poética del abandono y, de una manera parecida a E. A. Parra y Herlinghaus, establece un vínculo estrecho entre esa poética y el norte mexicano donde recibe su principal impulso. Además, como Herlinghaus, Yépez vincula el abandono poético con implicaciones políticas y éticas, alegando que se pone al servicio del pueblo marginado. Pero a Yépez sobre todo le interesa explicar por qué los nuevos narradores mexicanos y los protagonistas de la crítica literaria en México desautorizan sistemáticamente esta literatura proveniente del norte. Estima que las normas que manejan para deslindar el canon literario en última instancia provienen del ámbito político. Son las políticas gubernamentales las que estimulan la "perfección" de la obra de arte, ya que el gobierno no quiere "enunciaciones literarias que considere revoltosas, panfletarias, testimoniales o vulgares. [ . . . ] La obra artística no debe manifestar a nivel afectivo o lingüístico marcas directas o frecuentes del descontento popular" $(2015,92)$. Por lo tanto, las normas que los escritores mexicanos deben acatar se imponen desde el Parnaso cultural, los espacios de decisión políticos y el centro geográfico del país, denigrando

13. Su razonamiento hace pensar en lo dicho por Campobello sobre la gente de su tierra, del norte: "Silenciosamente, se adhiere al paisaje, sus pasos son lentos, sus voces, suaves, sólo dicen sílabas contadas” $(2006,94)$. 
muchos textos narrativos provenientes del norte porque, para decirlo con palabras de Prieto, el abandono poético que estos textos manifiestan está al servicio de un abandono político, de demandas subalternas. En la producción de la genuina cultura patria, no caben las huellas populares e iletradas. ${ }^{14}$

En el debate, vuelve a aparecer el calificativo de lo delgado, pues, dentro de la narco-narrativa, uno de estos críticos del centro al que Yépez dirige sus dardos, Christopher Domínguez Michael, estima que la novela Trabajos del reino, del escritor hidalguense Yuri Herrera, es digna de respeto y constituye una excepción porque, según él, logró crear una lengua literaria "adelgazada" (en Martínez Yépez 2015, 89). Es de suponer que Domínguez Michael y Prieto entienden lo delgado de otra manera. Para el primero, implica una depuración formal que se liberó de la servidumbre de lo social, mientras que, para el segundo, señala una escritura que se deshace de los ornatos de lo literario para, así, mantenerse atada al campo de las demandas y crisis sociales. En otro texto, que Yépez no cita, Domínguez Michael se refirió a la obra de Campobello con calificativos que hacen pensar en la narradora niña de Cartucho, sentada debajo de su mesa, porque la sitúa entre otros "escritores-artesanos que son el bajo clero de la revolución” (Domínguez Michael 1989, 46) y que cuentan la guerra en "épica menor" (45). Sobra decir que en esta apreciación la palabra "menor" no remite a una perspectiva subalterna sino que relega su obra a una categoría literaria inferior, una que "carece del aliento crítico de las grandes creaciones" (49). ${ }^{15}$

\section{Reflexiones finales}

Por supuesto, Yépez simplifica y generaliza indebidamente, lo cual por otra parte se entiende en vista del propósito polémico de su análisis. Así, el caso de Rulfo ilustra que hay excepciones

14. En un artículo posterior, publicado en un número de Revista de Literatura Mexicana Contemporánea dedicado a las prácticas de invisibilización que afectan el campo literario mexicano, Yépez alude a Campobello (y a Elena Garro) para demostrar cómo algunas obras se revalorizan después de mucho tiempo, cooptadas por "grupos que se benefician de su recuperación para afianzar sus poderes hegemónicos residuales o emergentes" $(2017,15)$.

15. Es apropiado atribuir a la obra de Campobello el rasgo de menor en el sentido de Gilles Deleuze y Felix Guattari (1975), como ha hecho Florence Olivier (2016, 233). Campobello aplica en efecto la recomendación de ambos filósofos, es decir, oponer el carácter oprimido al opresor de su propia lengua, encontrar los puntos de la no cultura, del subdesarrollo de la lengua, "las zonas de tercer mundo lingüístico por donde una lengua se escapa, un animal se entra, una disposición se conecta" (Deleuze y Guattari 1975, 47; traducción mía). 
Vanden Berghe, Presencia, posibilidades y posiciones de la escritura errante en México

importantes porque, practicante consecuente de la errancia, se ha convertido en uno de los escritores más canonizados de la literatura mexicana. ${ }^{16}$ Esto no quita que Yépez ofrezca un argumento, sin duda entre muchos otros, para explicar la ausencia de México en el estudio de Prieto. ${ }^{17}$ La mala escritura tendría una visibilidad reducida en el país porque cierta crítica canónica tiende a silenciar lo que considera fuera de la norma de la "forma perfecta", porque desvía la mirada de las escrituras errantes a las que condena al ostracismo: no respetan las normas estéticas dictadas por el centro que, al contrario, estimula lo que Prieto ha llamado escrituras gordas y redondas. A su vez, estas escrituras dietéticas contestan desde la literatura el poder político hegemónico. Las interpretaciones de E. A. Parra, Herlinghaus y Yépez confieren a los rasgos que he calificado en función del concepto de errancia un lugar esencial en las prácticas literarias norteñas, lo cual significa que, a la distancia de Campobello de la doxa política y los habitus culturales, se les añade una marginación geográfica.

Sin duda hay otras circunstancias que contribuyen a impedir que muchos autores y obras entren en el panteón. En cuanto a Campobello, habrá incidido el hecho de que, siendo mujer, escribiera sobre la violencia y la guerra. En su persona también se instala una tensión entre su apoyo a los olvidados y la gente pobre por una parte, y, por otra, su estilo de vida en la ciudad de México donde gozaba del lujo que condena en sus libros, como ilustran el retrato que hizo de ella Elena Poniatowska (2000) y las fotos incluidas en su biografía escrita por Jesús Vargas Valdés y Flor García Rufino (2013). Pese a esto, o quizás por esto mismo y para hacerse perdonar, desde la ciudad de México la escritora recalcaba los abandonos que había representado y asumido en sus libros sobre el norte. Lo hizo por ejemplo en 1960, en el prólogo que escribió para sus libros reunidos, al exclamar: "iEra una bárbara del norte de México ! iY así quería escribir, quería opinar !" (Campobello 2006, 110). ${ }^{18}$ Estas palabras merecen un comentario final.

Cuando las situamos en el marco latinoamericano, despunta el espíritu intempestivo que Prieto ve "intermitentemente [en] el campo de las vanguardias y los discursos revolucionarios del siglo

16. Yépez dedicó varios artículos críticos a cómo se ha efectuado esta canonización.

17. Con independencia de si uno esté de acuerdo con su modo de calificar a la narco-novela.

18. En otros textos suyos la palabra bárbaro se refiere a los apaches (Vanden Berghe 2013, 133). 
XX" $(2016,40)$. También se conectan con las vanguardias latinoamericanas porque suponen un fuerte entronque con la tradición cultural local y se distancian de la órbita nacional (21). Cuando interpretamos las exclamaciones en función del ámbito nacional mexicano, vemos que la autora considera su país al mismo tiempo como propio y como alejado, su geografía siendo el norte, un espacio en el que se ubica con orgullo. Con la palabra bárbara, señala el rechazo que su escritura sufre por parte de los supuestos civilizados quienes son, en realidad, los verdaderos bárbaros, a los que acusa en este mismo texto: "La injusticia, la barbarie de estos nuevos ricos mexicanos hartos de dinero, del dinero que robaban a este pueblo" (Campobello 2006, 99). ${ }^{19}$

En las exclamaciones de Campobello, aparece una cuadruple asociación que se declina en dos pares: entre una forma de "escribir" (poética) que a su vez supone una forma de "opinar" (política), asociación que ya hemos comentado antes; y entre el norte y la barbarie. Al asociar este norte con la barbarie, lo representa como un espacio de desviación frente a la razón y la cultura centrales, un espacio donde se deviene plebeya y donde se suspenden ciertas ideas de lo que es la buena literatura, donde medran los imaginarios disidentes pero culturalmente productivos. En estos sentidos, y por el rechazo de la supuesta civilización que esta exclamación también incluye, su gesto es una proclama de descolonización comparable al de Atahualpa cuando arroja el libro que le tiende el conquistador como acto simbólico de vasallaje. A Atahualpa la resistencia a la subyugación le cuesta la vida, a Nellie Campobello, el ser apartada de la vida literaria. Según Prieto, Atahualpa rechaza "la letra europea, y $[\ldots]$ la razón de dominio en ella inscrita" $(2016,30)$. Pero este libro rechazado, la Biblia, tiene una representatividad múltiple y ha venido a ocupar una posición diferente en la literatura mexicana, ya que es probable que Campobello se haya inspirado en él para elaborar su estilo errante empático con los subalternos y su forma de representar la violencia. También es significativo que se califique con el adjetivo bárbaro, porque así subraya y reivindica el carácter errante de su escritura: de etimología griega, bárbaro significa extranjero o, aun, "el que habla balbuceando", es decir, el que habla mal.

19. El hecho de que Campobello se hubiera negado a ir a la escuela y criticara el aparato escolar es otra manera mediante la cual mostró su rechazo de los mecanismos reproductores de los valores simbólicos de la nación, pues, como demostró Beatriz González Stephan, ya desde el siglo XIX "leer y escribir en términos nacionales equivalía a control. Específicamente control de las libertades ‘bárbaras”' (1996, 223). 
Vanden Berghe, Presencia, posibilidades y posiciones de la escritura errante en México

\section{Referencias bibliográficas}

Aguilar Mora, Jorge. 1991. Una muerte sencilla, justa, eterna: Cultura y guerra en la Revolución mexicana. México: Era.

Attala, Daniel, y Geneviève Fabry, eds. 2016. La Biblia en la literatura bispanoamericana. Madrid: Trotta.

Auerbach, Erich. (1946) 2011. Mimesis: la representación de la realidad en la literatura occidental. México: FCE.

Avechuco Cabrera, Daniel. 2017. "La Revolución narrada desde los márgenes: representaciones anómicas de la violencia en Cartucho, de Nellie Campobello". Literatura mexicana 20 (1): 69-98.

Campobello, Nellie. 1940. Apuntes sobre la vida militar de Francisco Villa. México: EDIAPSA.

- 2000. Cartucho: relatos de la lucha en el norte de México. México: Era.

_ 2006. Las manos de mamá; Tres poemas; Mis libros. México: Factoría Ediciones.

Carballo, Emmanuel. 1965. Diecinueve protagonistas de la literatura mexicana del siglo $X X$. México: Empresa Editorial.

Custodio, Álvaro. 1975. El corrido popular mexicano: su historia, sus temas, sus intérpretes. Coleccion Los Juglares 27. Madrid: Jucar.

De Beer, Gabriella. 1979. "Nellie Campobello, escritora de la Revolución mexicana”. Cuadernos Americanos, n. $^{\circ}$ 223, 212-19.

Deleuze, Gilles, y Felix Guattari. 1975. Kafka: Pour une littérature mineure. París: Les éditions de minuit.

Domínguez Michael, Christopher. 1989. Antología de la narrativa mexicana del siglo $X X$. Vol. 1. México: FCE.

DRAE (Diccionario de la Real Academia Española). Accessed September 10, 2020. https://dle.rae.es.

Fornet, Jorge. 1994. Reescrituras de la memoria: novela femenina $y$ revolución en México. La Habana: Editorial Letras Cubanas.

González Stephan, Beatriz. 1996. "Políticas de higienización: la limpieza del cuerpo y lengua nacionales (siglo XIX)". En Asedios a la beterogeneidad cultural: libro de bomenaje a Antonio Cornejo Polar, coord. por José Antonio Mazzotti y Juan Zevallos Aguilar, 217-48. Philadelphia: Asociación Internacional de Peruanistas.

Gutiérrez de Velasco, Luzelena. 2006. "Pancho Villa imaginado por Nellie Campobello". En Nellie Campobello: la revolución en clave de mujer, coord. por Laura Cázares H., 95-104. México: Conaculta, Universidad Iberoamericana, Tecnológico de Monterrey.

Héau de Giménez, Catalina. 1992. Así cantaban la revolución. México: Grijalbo.

Herlinghaus, Hermann. 2009. Violence without Guilt: Ethical Narratives from the Global South. New York: Palgrave Macmillan.

Izquierdo, Lucas. 2013. "Nellie Campobello's Cartucho (1931): Bandits, Politics, and Death". Revista Canadiense de Estudios Hispánicos 37 (2): 339-54. 
Linhard, Tabea Alexa. 2005. Fearless Women in the Mexican Revolution and the Spanish Civil War. Columbia: University of Missouri Press.

Lohfink, Norbert. 1990. Violencia y pacifismo en el Antiguo Testamento. París: Desclée de Brouwer.

Marco González, Ana. 2013. "Presencia de pautas narrativas de la tradición oral y popular en Cartucho de Nellie Campobello". Revista de Dialectología y Tradiciones Populares 68 (1): 167-89.

Martínez, Josebe. 2015. Nellie Campobello o la Revolución encarnada (México corporizado en un insólito "Cartucho”). Serie Monografías Transatlánticas 3. Madrid: Del Centro.

Martínez Yépez, Heriberto. 2015. "Dictadura de la forma perfecta: crítica canónica, narrativa contemporánea y desautorización de lo narcoliterario en México". Hispanic Journal 36 (2): 103-20.

—. 2017. "Hacia una teoría de la invisibilización en la literatura mexicana contemporánea". Revista de Literatura Mexicana Contemporánea 23 (72): 13-17.

Menchú, Rigoberta, y Elisabeth Burgos. 1987. Me llamo Rigoberta Menchú y así me nació la conciencia. México: Siglo XXI.

Mendoza, Vicente T. [1954] 1995. El corrido mexicano. Colección Popular 139. México: Fondo de Cultura Económica.

Meyer, Jean. 1974. La cristiada. Vol. 3, Los cristeros. México: Siglo Veintiuno.

Olivier, Florence. 2016. "Épica en modo menor o guerrilla narrativa en Cartucho de Nellie Campobello". En Equestrian Rebels: Critical Perspectives on Mariano Azuela and the Novel of the Mexican Revolution, coord. por Roberto Cantú, 229-43. Newcastle upon Tyne: Cambridge Scholars.

Pacheco, Carlos. 2016. La comarca oral revisitada. Bogotá: Universidad Nacional de Colombia.

Parle, Dennis J. 1985. "Narrative Style and Technique in Nellie Campobello's Cartucho". Kentucky Romance Quarterly 32 (2): 201-11.

Parra, Eduardo Antonio. 2004. "El lenguaje de la narrativa del norte de México”. Revista de Crítica Literaria Latinoamericana 30 (59): 71-77.

Parra, Max. 2005. Writing Pancho Villa's Revolution: Rebels in the Literary Imagination of Mexico. Austin: University of Texas Press.

Perelman, Bob. 1993. "Parataxis and Narrative: The New Sentence in Theory and Practice". American Literature 65 (2): 313-24.

Poniatowska, Elena. 2000. Las siete cabritas. México: Era.

Prieto, Julio. 2011. "Sobre ilegibilidad y malas escrituras en Hispanoamérica”. Ínsula: Revista de Letras y Ciencias Humanas 777, 2-4.

- 2016. La escritura errante: ilegibilidad y politicas del estilo en Latinoamérica. Madrid: Iberoamericana.

Rama, Ángel. [1984] 2007. Transculturación narrativa en América Latina. Buenos Aires: El Andariego.

Rodríguez, Blanca. 1998. Nellie Campobello: eros y violencia. México: UNAM. 
Vanden Berghe, Presencia, posibilidades y posiciones de la escritura errante en México

Sánchez Prado, Ignacio M. 2018. "Mexican Revolution and Literary Form:

Reflections on Nellie Campobello's Cartucho". En Mexican Literature in Theory, coord.por Ignacio M. Sánchez Prado, 75-92. New York: Bloomsbury.

Vanden Berghe, Kristine. 2013. Homo ludens en la Revolución: una lectura de Nellie Campobello. Madrid: Iberoamericana.

- 2016. "Ethos y postura de Nellie Campobello". En Equestrian Rebels: Critical Perspectives on Mariano Azuela and the Novel of the Mexican Revolution, coord. por Roberto Cantú, 202-28. Newcastle upon Tyne: Cambridge Scholars.

- 2017. "Parecidos estilísticos entre Juan Rulfo y Nellie Campobello". En "El Llano en llamas", "Pedro Páramo" y otras obras (en el centenario de su autor), coord. por Pedro Angel Palou y Francisco Ramírez Santacruz, 301-26. Madrid: Iberoamericana.

Vargas Valdés, Jesús, y Flor García Rufino. 2013. Nellie Campobello: mujer de manos rojas. Chihuahua: Gobierno del Estado de Chihuahua, Secretaría de Educación, Cultura y Deporte. 